\title{
ACIDENTES OCUPACIONAIS COM PROFISSIONAIS DA EQUIPE DE ENFERMAGEM DE UM HOSPITAL DO VALE DO PARAÍBA PAULISTA
}

\section{ACCIDENTS WITH PROFESSIONAL NURSING STAFF OF A HOSPITAL IN THE VALE DO PARAÍBA PAULISTA}

\author{
Vanessa de Brito Poveda ${ }^{1}$ \\ Luciana Souza Guerra² \\ Olga Lúcia Teixeira de Carvalho ${ }^{2}$ \\ Pâmela Luiza Marques da Silva² \\ Maria Odete Pereira de Araújo $^{3}$
}

RESUMO: Objetivou-se descrever o perfil dos acidentes ocupacionais ocorridos com a equipe de enfermagem de um Hospital do Médio Vale do Paraíba Paulista, de dezembro de 2007 a novembro de 2008, analisando o conhecimento do profissional quanto ao seguimento sorológico, adoção das medicações prescritas, número de abandonos e identificação de alterações sociais oriundas do acidente. Trata-se de um estudo de natureza quantitativa e qualitativa. Os dados foram coletados por meio de um questionário semiestruturado, baseado no Manual do Ministério da Saúde sobre Recomendações para o Atendimento e Acompanhamento de Exposição Ocupacional a Material Biológico HIV e Hepatites B e C (2004) e a Ficha de Comunicação de Acidente de Trabalho. Os resultados foram analisados na forma descritiva e matemática estatística e as entrevistas submetidas à análise de conteúdo. Foram entrevistados 10 profissionais, dentre estes, cinco (50\%) vivenciaram o segundo acidente, sendo sete (70\%) ocasionados por material perfurocortante, sete (70\%) conheciam a importância da medicação antiretroviral, quatro (40\%) iniciaram a terapêutica e dois (20\%) finalizaram o tratamento e todos os profissionais vivenciaram sentimentos perturbadores diante da possibilidade de terem sido infectados pelo HIV. Conclui-se que a implantação de ações educativas aos profissionais de enfermagem é necessária para melhor entendimento aos riscos de exposição ocupacional.

Palavras-chave: enfermagem; acidentes de trabalho; exposição ocupacional.

ABSTRACT: The research analyzed labor accidents occurring in a nursing team from a hospital in the middle of the Paraíba Valley, SP in the period from December 2007 to November 2008. The professional knowledge about the serum procedure, medical prescriptions, number of abandonments, and identification of social alterations that resulted from the accident were analyzed. The study was quantitative and qualitative. The data were collected through a semi-structured questionnaire based on the Manual of the Brazil Ministry of Health: about recommendations to the first attending and following of occupational exposure to Biologic material with HIV and hepatitis $B$ and $C$ (2004) was well as the labor accident communication form. The results were then analyzed descriptively and statistically and the interviews were submitted to content analysis. Ten workers were interviewed, and in this group five (50\%) have had the second accident, seven (70\%) had the accident with cutting materials, seven (70\%) know the importance of antiretroviral medication, four (40\%) have begun the treatment, and two (20\%) have finished the treatment. All of them were afraid of having contracted HIV. It can be concluded that education must be provided for a better comprehension of the labor exposure risks.

Keywords: nursing; occupational accidents; occupational exposure.

\footnotetext{
${ }^{1}$ Enfermeira. Doutorado e Pós-doutorado em Enfermagem pela Escola de Enfermagem de Ribeirão Preto da Universidade de São Paulo. Docente da Universidade do Vale do Paraíba e Faculdades Integradas Teresa D'Ávila. E-mail: vbpoveda@yahoo.com.br.

${ }^{2}$ Enfermeiras. E-mails: luciana_29guerra@hotmail.com; olga_tcarvalho@hotmail.com; pamelaluiza@yahoo.com.br.

${ }^{3}$ Enfermeira. Doutora em Ciências pelo Programa de Pós-Graduação em Enfermagem da Escola de Enfermagem da Universidade de São Paulo. Pós-doutoranda do Programa Nacional de Pós-doutorado - PNPD/CAPES no Programa de PósGraduação em Enfermagem da Escola de Enfermagem da Universidade de São Paulo. E-mail: m.odetepereira@gmail.com.
} 


\section{INTRODUÇÃO}

Desde o surgimento da AIDS (Acquired Imuno Deficiency Syndrome/Síndrome da Imunodeficiência Adquirida) na década de 1980, os profissionais da saúde, especificamente da enfermagem, estão vulneráveis à aquisição do HIV (Vírus da Imunodeficiência Humana), em função de suas atividades profissionais (MINISTÉRIO DA SAÚDE, 2006).

O profissional de enfermagem, no âmbito hospitalar, muitas vezes presta assistência contínua de maneira insalubre, devido à grande demanda de clientes, número reduzido de recurso humano e o alto índice de intercorrências com a clientela atendida, aumentando assim o risco de ocorrência de acidente de trabalho (LIMA; PINHEIRO; VIEIRA, 2007).

A Lei Federal 8123/91, artigo 19 caput, conceitua acidente de trabalho como sendo todo evento que "ocorre pelo exercício do trabalho; acarreta perturbação funcional (doença física ou mental) ou lesão corporal; resulta em morte ou incapacidade laborativa temporária ou permanente, total ou parcial" (MINISTÉRIO DA PREVIDÊNCIA SOCIAL, 1991).

A exposição ocupacional, relacionada a risco biológico e vulnerabilidade da equipe de enfermagem, pode ocorrer de três formas, a saber: exposição percutânea, por meio da penetração da pele por material perfurante e cortante, que esteja contaminado com sangue ou outros líquidos; contato com mucosa, pela exposição ao sangue ou outros líquidos contaminados em contato direto com a mucosa ocular, nasal, oral ou genital e exposição cutânea (pele não íntegra), quando ocorre o contato com material biológico potencialmente contaminado e em grande volume com a pele (MINISTÉRIO DA SAÚDE, 2006).

Conforme determinado pela legislação, a Comunicação de Acidente de Trabalho (CAT) deve ser realizada com o objetivo de fornecer dados estatísticos da distribuição dos acidentes, suas respectivas ocorrências e nortear as indicações, aplicações e o controle das medidas preventivas (CHIODI; MARZIALE; ROBAZZI, 2007).

As medidas profiláticas para os profissionais expostos à transmissão sanguínea foram desenvolvidas a partir da epidemia do HIV/AIDS (MINISTÉRIO DA SAÚDE, 2004).

Em 1984 ocorreu a primeira confirmação de aquisição do HIV, nos Estados Unidos da América por uma enfermeira, durante perfuração acidental com agulha. No Brasil, o primeiro caso identificado pelo Ministério do Trabalho de aquisição ocupacional de HIV data de 1999 , ocorrido durante a realização de uma técnica de punção venosa por uma auxiliar de enfermagem (GIR et al., 2008).

Entretanto, não existem muitas evidências de que os profissionais de saúde estão mais predispostos à aquisição do HIV em comparação a população geral (MINISTÉRIO DA SAÚDE, 2006).

Para que ocorra a contaminação efetiva é preciso um conjunto de fatores interligados, relacionados ao acidente, tais como: a via, profundidade, tamanho e condições do inóculo, tempo de contato entre a fonte e o profissional; a fonte de infecção, observando-se o grau de viremia, uso de antiretrovirais e estágio da doença; 
se o profissional acidentado apresentava outras doenças de base; e, finalmente, as condições do atendimento inicial após o acidente (MINISTÉRIO DA SAÚDE, 2006).

Em 2002, a Organização Mundial de Saúde (OMS) estimava que dentre os 35 milhões de profissionais de saúde de todo o mundo, ocorriam em média três milhões de acidentes ocupacionais por ano, com exposição, aproximadamente de dois milhões de casos de Hepatite B, 900.000 casos de Hepatite $C$ e 300.000 casos de HIV (Vírus da Imunodeficiência Humana) (CASSOLI, 2006).

Diante dessa afirmativa, é necessário detectar se a categoria de enfermagem está apta a reconhecer e adotar medidas profiláticas pós-exposição ocupacional, sendo assim é imprescindível avaliar criteriosamente a informação e o perfil desses profissionais.

O objetivo deste estudo foi descrever o perfil dos acidentes ocupacionais entre profissionais da equipe de Enfermagem de um Hospital do Médio Vale do Paraíba Paulista, no período de dezembro de 2007 a novembro de 2008, analisando o conhecimento do profissional exposto ao acidente quanto à necessidade de seguimento sorológico e adoção das medicações prescritas, verificando a ocorrência de abandono do tratamento e os fatores casuais, identificando sentimentos e emoções emergentes no momento do acidente e reconhecendo as alterações oriundas do acidente ocupacional no âmbito social do profissional de enfermagem.

\section{METODOLOGIA}

Trata-se de um estudo de natureza qualitativa/quantitativa, que aferiu o conhecimento dos profissionais da equipe de enfermagem de um Hospital do Médio Vale do Paraíba Paulista, que se acidentaram no período entre dezembro de 2007 a novembro de 2008 e as emoções advindas do acidente ocupacional.

O estudo foi realizado em um hospital filantrópico, de médio porte, localizado no Médio Vale do Paraíba do Estado de São Paulo, com capacidade máxima de 200 leitos. A equipe de enfermagem era composta por 18 enfermeiros, 131 técnicos de enfermagem e 21 auxiliares de enfermagem.

O projeto foi aprovado pelo Comitê de Ética das Faculdades Integradas Teresa D'Ávila (CEP - FATEA), recebendo aprovação sob o número de protocolo 84/2008 em quinze de setembro de 2008 e atendendo às exigências da Resolução de n 196/96, de 10 de outubro de 1996 do Conselho Nacional de Saúde, referentes aos aspectos éticos quando da realização de pesquisa envolvendo seres humanos.

Obtidos o Termo de Consentimento da Instituição e dos participantes (Termo de Consentimento Livre e Esclarecido), foram agendadas as visitas para a coleta de dados, em dias e horários determinados e convenientes para todos os envolvidos. A coleta de dados ocorreu nos meses de novembro e dezembro de 2008.

A coleta de dados foi realizada por meio de um questionário semi-estruturado, elaborado pelas autoras, baseado no Manual do Ministério da Saúde sobre Recomendações para o Atendimento e 
Acompanhamento de Exposição Ocupacional a Material Biológico: HIV e Hepatites B e C (MINISTÉRIO DA SAÚDE, 2004) e a Ficha de Investigação de Acidente de Trabalho com Exposição à Material Biológico (MINISTÉRIO DA SAÚDE, 2008). O questionário foi analisado e aperfeiçoado através do Método de Validação Aparente e de Conteúdo, por três enfermeiras especialistas em Enfermagem do Trabalho. Os resultados foram digitados e tabulados eletronicamente, analisados na forma descritiva e matemático estatístico.

As entrevistas foram transcritas e transcriadas, segundo a História Oral, uma prática de apreensão de narrativas feita através do uso de meios eletrônicos e destinada a recolher testemunhos, promover análises de processos sociais do presente, e facilitar o conhecimento do meio imediato dos participantes (MEIHY; HOLANDA, 2007), e submetidas à análise de conteúdo pelas autoras, baseadas na Pesquisa Qualitativa em Saúde que faz relação dinâmica entre o mundo real e o sujeito, isto é, um vínculo indissociável entre o mundo objetivo e a subjetividade do sujeito que não pode ser traduzido em números (MINAYO, 2008).

\section{RESULTADOS E DISCUSSÃO}

A população selecionada no período de dezembro de 2007 a novembro de 2008 era constituída por 18 profissionais de enfermagem, sendo que a amostra final foi constituída por 10 profissionais de enfermagem, uma vez que não foram entrevistados: dois acidentados por estarem em férias, quatro em licença médica e dois rescindiram contrato de trabalho com a instituição pesquisada. Todos os sujeitos entrevistados pertencem ao sexo feminino $10(100 \%)$.

A literatura consultada indicou que os profissionais de enfermagem mais vulneráveis ao acidente ocupacional são os do sexo feminino em consequência ao número de mulheres que compõem a equipe hospitalar e que por muitas vezes realizam dupla ou tripla jornada de trabalho, para assim contribuírem com a renda familiar (RIBEIRO; SHIMIZU, 2007).

Quanto à idade, houve variação entre 21 anos e 55 anos, sendo que quatro (40\%) sujeitos estavam na faixa etária entre vinte e trinta anos, três (30\%) entre trinta e um e quarenta anos, dois (20\%) sujeitos entre quarenta e um cinquenta anos, e um (10\%) sujeito com faixa etária entre cinquenta e um e sessenta anos, com média de 34 anos de idade.

Diversos estudos indicam a que variação de idade dos profissionais de enfermagem, que se acidentam, está contida entre trinta e um e cinquenta anos, sendo classificados como adultos jovens, dado este que corrobora os resultados encontrados na instituição pesquisada (RIBEIRO; SHIMIZU, 2007; PINHO; RODRIGUES; GOMES, 2007).

Em relação ao grau de escolaridade, quatro (40\%) têm o ensino médio completo, um $(10 \%)$ ensino médio incompleto, dois (20\%) ensino superior completo e três $(30 \%)$ ensino superior incompleto. Quanto à categoria profissional um (10\%) era auxiliar de enfermagem, sete $(70 \%)$ técnicos de enfermagem e dois (20\%) enfermeiros.

A literatura científica indica que os profissionais da equipe de enfermagem mais 
expostos ao acidente de trabalho são os técnicos e auxiliares de enfermagem, dado que os profissionais que concluíram o ensino médio representam a maior parte da equipe de enfermagem no Brasil e também estão mais expostos em consequência do contato direto com os pacientes e o grande número de procedimentos realizados (CHIODI; MARZIALE; ROBAZZI, 2007; RIBEIRO; SHIMIZU, 2007; PINHO; RODRIGUES; GOMES, 2007; MALAGUTI et al., 2008).

Quanto à experiência profissional, cinco (50\%) dos sujeitos entrevistados atuavam na profissão entre um e cinco anos, dois (20\%) atuavam entre cinco e dez anos, e três (30\%) a mais de dez anos.

Opostamente aos resultados obtidos nesta pesquisa, quanto ao tempo de atuação profissional, os estudos indicam que os profissionais com maior tempo de experiência são os que mais se acidentaram, em virtude da escassez de treinamentos nas instituições e por se considerarem aptos para realizar procedimentos sem a utilização de EPI (equipamento de proteção individual) e os profissionais com menor tempo de experiência apresentam menores índices devido à atenção destinada ao momento da realização de procedimentos que envolvem fatores predisponentes ao acidente (PINHO; RODRIGUES; GOMES, 2007; ALMEIDA; BENATTI, 2007).

Relacionando os locais de ocorrência dos acidentes, verificou-se a predominância do setor de clínica médica, com quatro $(40 \%)$ dos casos, em seguida o pronto socorro e unidade de tratamento intensivo (UTI), ambos com dois (20\%) dos acidentes; e berçário e centro cirúrgico com um (10\%) incidente, cada.

Em geral, a clínica médica é apontada, dentre os setores hospitalares de ocorrência de acidentes ocupacionais, como o local de maior prevalência, devido ao grande fluxo de pacientes e intercorrências (CASSOLI, 2006; PINHO; RODRIGUES; GOMES, 2007; BALSAMO; FELLI, 2006).

Sobre o horário de trabalho, seis $(60 \%)$ trabalhadores de enfermagem desenvolviam suas atividades no período diurno e quatro $(40 \%)$ no período noturno. O período diurno é usualmente apontado como o horário de trabalho que possui o maior índice de ocorrência de acidentes ocupacionais em função da grande demanda de procedimentos e sobrecarga de serviço (SAILER; MARZIALE, 2007; PINHEIRO; ZEITOUNE, 2008).

Quando indagados a respeito do exercício de outras atividades, oito (80\%) indivíduos não exerciam outra atividade assalariada e dois (20\%) sim. Além disso, três $(30 \%)$ sujeitos cursavam a graduação em enfermagem. Estudos indicam que grande parte dos profissionais de enfermagem que se acidentam possui outro vínculo, seja empregatício e/ou educacional (SAILER; MARZIALE, 2007).

Observou-se, na amostra estudada, que cinco indivíduos (50\%) estavam vivenciando 0 segundo acidente perfurocortante, quatro (40\%) vivenciavam a experiência pela primeira vez e um (10\%) estava vivenciando o primeiro acidente com contato cutâneo com secreção sanguinolenta após procedimento de entubação endotraqueal. Estudos revelam que as atividades profissionais desenvolvidas pela equipe de enfermagem 
acarretam diversas exposições ocupacionais, evidenciando o alto número de indivíduos que sofreram vários acidentes de origem percutânea e ou contato com a mucosa. No presente estudo, a instituição pesquisada caracterizou esta realidade (ALMEIDA; BENATTI, 2007; BALSAMO; FELLI, 2006; PINHEIRO; ZEITOUNE, 2008; SARQUIS; FELLI, 2008; CASTANHA; MACHADO; FIGUEIREDO, 2007).

Verificou-se que os acidentes ocupacionais ocorreram no momento da administração de medicação endovenosa, um $(10 \%)$ dos casos, punção venosa para coleta de sangue; dois (20\%), desprezo inadequado de material perfurocortante; três (30\%), reencape de agulha; três (30\%), em contato com mucosa por secreção após procedimento de entubação endotraqueal, em um (10\%) caso.

Dentre os acidentes nove (90\%) foram ocasionados por material perfurocortante, sendo que os objetos envolvidos foram agulhas em sete $(70 \%)$ dos casos; lâmina de barbear e escalpe em um (20\%) dos casos cada; e um (10\%) incidente com cânula endotraqueal.

Cabe ressaltar que a maioria das ocorrências de acidentes ocupacionais no âmbito hospitalar é de natureza perfurocortante, originados por atitudes muitas vezes errôneas, como o reencape de agulha, o desprezado inadequado de material perfurocortante e grande demanda de punção venosa (ALMEIDA; BENATTI, 2007; BALSAMO; FELLI, 2006; PINHEIRO; ZEITOUNE, 2008; SARQUIS; FELLI, 2008; CASTANHA; MACHADO; FIGUEIREDO, 2007). Quando se refere à utilização do EPI, cinco $(50 \%)$ não utilizavam no momento do acidente, enquanto os sujeitos restantes $\operatorname{sim}$

Mediante 0 número elevado de acidentes de trabalho e os fatores de risco a aquisição profissional do HIV (Vírus da Imunodeficiência Humana), HBV (Vírus da Hepatite B), HCV (Vírus da Hepatite), viu-se a necessidade de se elaborar determinações de Biossegurança, que visam à implantação de normas e procedimentos confiáveis e adequados ao âmbito hospitalar, com 0 objetivo de preservar a saúde dos profissionais de enfermagem (SCHEIDT; ROSA; LIMA, 2006).

Dentre as condutas exigidas, encontra-se o uso de EPIs (equipamento de proteção individual) e EPCs (equipamento de proteção coletiva), com o propósito de reduzir a contaminação do profissional ao sangue e fluidos corporais (CORREIA; DONATO, 2007).

Entretanto, estudos indicam que frequentemente os profissionais de enfermagem muitas vezes ignoram a utilização desses equipamentos, em virtude de alguns preceitos como a desvalorização das técnicas preventivas, ausência de treinamentos específicos e escassez de recursos materiais (ALMEIDA; BENATTI, 2007; CARVALHO, ARAUJO, 2008; MEDEIROS et al., 2007).

Diante das condutas a serem tomadas após o acidente ocupacional, nove (90\%) relataram conhecimento e um (10\%) as desconhecia. Quanto às providências pós-exposições realizadas pelos sujeitos, além da Comunicação de Acidente de Trabalho (CAT) que foi efetuada em todos os casos, oito (80\%) referem ter lavado o local com água e sabão, e três (30\%) aplicaram 
solução anti-séptica.

As condutas pós-exposição ocupacional que devem ser realizadas pelo profissional de enfermagem acidentado são preconizadas pelo Ministério da Saúde. É indicada a lavagem imediata e exaustiva do local atingido com água e sabão, podendo ser utilizado também soluções anti-sépticas degermantes nas exposições cutâneas ou percutâneas. Nos casos que envolvem exposição de mucosa, deve se adotar imediatamente a irrigação do local com água corrente ou solução fisiológica (MINISTÉRIO DA SAÚDE, 2004).

A Comunicação de Acidente de Trabalho (CAT) é a primeira conduta a se realizar após a exposição ocupacional com a finalidade de fomentar dados pertinentes aos riscos biológicos e subsidiar as condutas preventivas, evitando subnotificações (MINISTÉRIO DA SAÚDE, 2004; ALMEIDA; BENATTI, 2007; CASTANHA; MACHADO; FIGUEIREDO, 2007).

Todos referam conhecer a importância dos exames, sendo que o esquema do acompanhamento sorológico havia sido completando em nove (90\%) e um (10\%) caso ainda estava em fase de realização dos exames. A realização de exames no paciente fonte foi efetivada em sete (70\%) dos casos e em três (30\%) não foi possível devido ao fato do paciente fonte ser desconhecido.

Ocorrido 0 acidente, 0 acompanhamento sorológico pós-exposição ocupacional deve ser instituído realizando novos exames após seis semanas, três e seis meses. Em caso de o paciente fonte ser portador de HIV, deve-se repetir o exame também doze meses após 0 acidente (MINISTÉRIO DA SAÚDE, 2004).

O acompanhamento do profissional exposto a material biológico potencialmente contaminado, quanto à adoção ao seguimento sorológico, garante-lhe 0 sucesso na prevenção de uma possível contaminação pelos vírus HIV, HVB (Vírus da Hepatite B) e HVC (Vírus da Hepatite C), favorecendo o diagnóstico e tratamento precoce. A não adesão a este seguimento sorológico ocorre muitas vezes em virtude de fatores intrínsecos e extrínsecos relacionados ao profissional de enfermagem acidentado (CASSOLI, 2006).

Em relação à cobertura vacinal contra hepatite $B$, todos estavam vacinados. Com base em estudos, o esquema completo de vacinação contra Hepatite $B$ confirma a diminuição dos coeficientes de morbidade indicativos das contaminações ocupacionais relativas aos profissionais de enfermagem (PINHEIRO; ZEITOUNE, 2008; CASTANHA; MACHADO; FIGUEIREDO, 2007; DAMASCENO et al., 2006).

Quanto à existência de Protocolo na Instituição, nove (90\%) referem que conhecem a existência do mesmo e um $(10 \%)$ desconhecia. Os treinamentos de prevenção de acidentes foram realizados por apenas cinco $(50 \%)$.

O estabelecimento de metas que visam à promoção e à prevenção de acidentes ocupacionais no ambiente hospitalar têm o propósito de manter a integridade física e mental do profissional de enfermagem e devem ser instituídas por meio da criação de Protocolos e Educações Continuadas (CARVALHO; ARAÚJO, 2008).

A importância da medicação 
antiretroviral era conhecida por sete $(70 \%)$ dos sujeitos e três (30\%) desconheciam a importância. Os efeitos colaterais eram conhecidos por seis $(60 \%)$ dos sujeitos da pesquisa e quatro (40\%) os desconheciam.

O tratamento antiretroviral foi instituído em quatro (40\%) dos casos, destes, três $(30 \%)$ consideraram válido o uso e um $(10 \%)$ não. O tratamento foi finalizado em dois $(20 \%)$ dos casos e a desistência do tratamento ocorreu em dois $(20 \%)$ casos, devido aos efeitos colaterais da medicação, que foram referidos como intolerâncias gastrintestinais.

A utilização da terapêutica antiretroviral pode ser analisada pelo profissional de enfermagem acidentado que conhece sua importância e indicação, como uma opção benéfica, que conota uma redução significativa da susceptibilidade de uma possível contaminação. Entretanto os números de interrupção da terapêutica antiretroviral são expressivos em consequência de diversas barreiras como os eventos adversos e a exigência do horário para ingestão dos medicamentos, que influenciam de maneira negativa a adesão efetiva dos profissionais de enfermagem expostos a material biológico (MALAGUTI et al., 2008; ALMEIDA; BENATTI, 2007; SAILER; MARZIALE, 2007; MEDEIROS et al., 2007).

Ressaltamos que as medidas terapêuticas adotadas pós-exposição ocupacional não são totalmente eficientes. Existem relatos documentados de aquisição de HIV por profissionais de saúde que utilizaram adequadamente a medicação antiretroviral, sendo primordial a implantação de medidas profiláticas e ações educativas para reduzir os números de acidentes de trabalho (MINISTÉRIO DA SAÚDE, 2006).

A desistência à terapêutica antiretroviral está relacionada a fatores como: o número elevado de reações adversas, falta de adequação entre o horário de ingestão do medicamento e a rotina do profissional, falta de compreensão da prescrição médica e ausência de conhecimento sobre as consequências causadas pela interrupção do antiretroviral trabalho (MINISTÉRIO DA SAÚDE, 2004).

Quando questionados sobre as medidas preventivas realizadas com 0 objetivo de evitar uma possível transmissão secundária, quatro (40\%) referiram a utilização de preservativos durante as relações sexuais; cinco (50\%) optaram pela não doação de sangue, órgão, esperma ou outros; seis $(60 \%)$ evitaram a gravidez ou amamentação; e dois (20\%) não realizaram nenhuma prevenção.

As condutas que devem ser adotadas pelos profissionais de enfermagem acidentados, para evitar uma possível transmissão secundária são diversas e incluem medidas como: utilizar preservativos durante as relações sexuais; evitar a gravidez e amamentação; e não doar sangue e órgãos. Todas estas precauções visam proteger o profissional e os indivíduos que fazem parte do seu convívio íntimo, sendo muitas vezes enfrentadas de maneira angustiante, pois altera de maneira brusca a rotina de todas as pessoas envolvidas (SARQUIS et al., 2005; ALMEIDA, 2003).

Assim, é válido afirmar que, quando o profissional de enfermagem se acidenta, ele tem grandes chances de desenvolver desgastes em sua condição biopsicossocial (LIMA; PINHEIRO; VIEIRA, 2005). 
Após a exposição, apenas cinco (50\%) dos sujeitos procuraram informações sobre Hepatites, HIV e AIDS; e em quatro (40\%) casos essa procura de informações foi através do diálogo com outros profissionais; e um (10\%) foi por meio de pesquisas internet e livros.

A busca por conhecimento acerca dos riscos relacionados à exposição a material biológico potencialmente contaminado pelo profissional de enfermagem, só ocorre após a vivência do acidente, e se caracteriza como um instrumento que esclarece dúvidas e traz conforto no momento de fragilidade (ALMEIDA, 2003).

Em sete (70\%) dos casos, a assistência médica foi considerada satisfatória; em um (10\%) caso a assistência médica foi considerada insatisfatória; e em dois $(20 \%)$ referem que não houve necessidade de serviço médico.

O acompanhamento clínico e laboratorial efetivo depende das características de adesão do profissional de enfermagem acidentado e a importância que este conota ao processo. Para obtenção de tal sucesso a Instituição comprometida em realizar esta assistência, precisa utilizar estratégias eficazes que garantam um monitoramento biopsicossocial (SARQUIS et al., 2005; ALMEIDA, 2003; VIEIRA; PADILHA, 2008).

\subsection{Acidentes ocupacionais e as emoções dos profissionais de enfermagem acidentados}

No contexto que engloba as emoções derivadas do acidente ocupacional, os sentimentos vivenciados foram diversos, entretanto, alguns merecem destaque devido ao impacto causado na vida do profissional acidentado.

As emoções como medo, raiva, nervoso, incapacidade, vazio, desespero e ansiedade, são decorrentes dos transtornos psicológicos que o acidente ocupacional causa na vida dos profissionais de enfermagem e foram evidenciadas nas declarações a seguir:

“... Medo! Fiquei apreensiva por não saber se o paciente era portador de alguma patologia transmissível"... "Senti-me vulnerável frente à possibilidade de contaminação, pois o paciente era homossexual e seu companheiro havia morrido em decorrência da AIDS. Foi como se eu realmente tivesse contraído a doença"... "Raiva, preocupação com a família, sentimento de morte"... "Fiquei nervosa, frustrada, senti um vazio. O desespero tomou conta de mim."

A vivência de sentimentos perturbadores pelos profissionais de enfermagem acidentados decorrem da insegurança diante da possibilidade de terem sido infectados pelo vírus do HIV, em primeira instância, seguido do vírus HBV e HCV (LIMA; PINHEIRO; VIEIRA, 2007; DAMASCENO et al., 2006).

Em uma pesquisa a respeito das dimensões psicológicas derivadas do acidente ocupacional, detectou-se que os profissionais de enfermagem que se acidentam vivenciam sentimentos e sensações diversas, variando conforme o grau de conhecimento pertinente ao assunto, as experiências já vivenciadas e os 
valores, conceitos e enfrentamentos atribuídos à problemática, irão depender da subjetividade do indivíduo (SARQUIS; FELLI, 2008).

A suscetibilidade de mudança permanente ou temporária dos processos de saúde-doença, a proximidade com a morte e a preocupação com o preconceito que poderá ser sofrido, expõe o profissional de enfermagem acidentado a lacunas da subjetividade, causando danos não mensuráveis.

\subsection{Profissionais de enfermagem acidentados $e$ as condutas pós- exposição ocupacional}

Ao serem questionados acerca das condutas a serem tomadas imediatamente após a ocorrência do acidente ocupacional, constatamos que houve unanimidade entre os entrevistados, alegando estarem cientes das condutas a serem tomadas, descritas nas falas a seguir:

"Minha primeira ação foi acionar a supervisora de enfermagem do hospital. Em seguida realizamos a Comunicação do Acidente de Trabalho e entramos em contato com o infectologista para iniciar a terapêutica antiretroviral." Outra relata que "... No momento do acidente estava muito abalada, por isso as condutas foram tomadas pelas outras funcionárias do setor."

A literatura relata que as condutas pósacidente ocupacional devem ser realizadas de forma sequencial, iniciadas pelos cuidados do local atingido; acionamento imediato da supervisão de enfermagem; realização da Comunicação de Acidente de Trabalho (CAT); coleta de dados referentes às causas que levaram ao acidente, para que sejam tomadas as medidas cabíveis quanto a uma possível adoção de terapêutica antiretroviral e continuidade da orientação individual ao profissional acidentado e acompanhamento clínico e laboratorial (MINISTÉRIO DA SAÚDE, 2004; CASTANHA; MACHADO; FIGUEIREDO, 2007).

O estabelecimento de protocolos institucionais direcionados às condutas pós-exposição ocupacional viabilizam a continuidade do fluxo de informação, orientam e conferem segurança aos profissionais de enfermagem diante da decisão a ser realizada.

\subsection{Profissionais de enfermagem acidentados e 0 apoio psicológico}

Quando questionados a respeito do apoio psicológico oferecido pela rede social dos profissionais acidentados, foi mencionado de maneira expressiva que esta questão não foi trabalhada dentro do contexto de vida. Entretanto, o escasso apoio psicológico oferecido foi de grande valia para aqueles profissionais de enfermagem que se acidentaram. No entanto, este apoio foi oferecido pela equipe de enfermagem do setor, e não por um psicólogo, conforme descrito a seguir:

"Não foi oferecido nenhum tipo de apoio psicológico e por isso me senti muito sozinha naquele momento"... "O apoio psicológico foi realizado pela equipe de enfermagem do setor onde eu trabalho. Eles estiveram sempre ao 
meu lado, me encorajando"... "A supervisora de enfermagem e toda a equipe do setor me ajudaram a enfrentar a situação e conversaram muito comigo. Meus familiares também ajudaram muito, foram bastante compreensivos."

Estudos demonstram que a possibilidade de uma contaminação, em decorrência de um acidente ocupacional, causa impacto e desestrutura o espaço profissional, social e pessoal, alterando significativamente as condições biopsicossociais (SCHEIDT; ROSA; LIMA, 2006). Sendo assim, o apoio psicológico é de fundamental importância para a saúde física e mental dos profissionais de enfermagem acidentados. (CASTANHA; MACHADO; FIGUEIREDO, 2007; VIEIRA; PADILHA, 2008)

Algumas instituições hospitalares não possuem um serviço especializado em atender os profissionais de enfermagem acidentados, fato que conota um descomprometimento muito grande com a saúde do trabalhador e gera questionamentos a respeito do serviço. Sendo assim, a equipe de enfermagem que está acompanhando toda a problemática vivenciada pelo profissional acidentado, se sensibiliza e oferece o apoio psicológico, mesmo que este não seja especializado.

\subsection{Os profissionais de enfermagem acidentados e o retorno dos resultados dos exames}

A angústia gerada pela espera dos resultados dos exames remete aos profissionais de enfermagem acidentados as percepções mais conflituosas durante todo o processo, enfatizada pelas falas:

"O meu primeiro pensamento foi com relação à minha família. Enquanto não obtive todos os resultados dos exames a paz não retornou ao meu lar. Pensava: e se der positivo, o que eu vou fazer?"... "Procurei afastar os pensamentos negativos e pensar somente em coisas boas para me distrair $e$ diminuir a angústia da espera. Foi muito difícil, não conseguia tirar os exames da cabeça"... "Senti um vazio tão grande, não tinha capacidade de lidar com a ansiedade até retornarem os exames. $O$ medo da morte se apoderou de mim."

O tempo de espera pelos resultados dos exames acarreta sentimentos avassaladores no profissional acidentado e nas pessoas de seu convívio íntimo, pela possibilidade de uma possível contaminação. Os retornos para realização do acompanhamento laboratorial tornam-se um dos momentos mais difíceis da exposição ocupacional (VIEIRA; PADILHA, 2008).

Em contrapartida, alguns profissionais de enfermagem mantiveram-se indiferentes ao acidente ocupacional. Essas declarações são frutos da falta de conhecimento acerca dos riscos de contaminação aos quais foram expostos.

"Meus pensamentos foram normais, eu estava calma, não me preocupei a respeito do assunto, a agulha era de insulina e de pouco calibre"... "Não pensei no assunto, me mantive calma e segura. Afinal, não 
era o meu primeiro acidente."

3.5 Os profissionais de enfermagem acidentados e a Comunicação do Acidente de Trabalho (CAT)

A Comunicação do Acidente de Trabalho (CAT) é fundamental para que se possa realizar o acompanhamento clínico do profissional acidentado e evitar subnotificações. Entretanto, diante desta problemática, é necessário que o profissional se sinta seguro para realizar tal procedimento. As declarações a seguir enfatizam essa questão.

"Senti-me segura, pois todos os procedimentos foram realizados, $e$ a Comunicação do Acidente de Trabalho é a primeira etapa deste processo"... "Confesso que não estava utilizando EPI no momento do acidente, entretanto essa falha não impediu de ter consciência da importância da Comunicação do Acidente de Trabalho"... "Fiquei super segura em comunicar o acidente de trabalho, pois a supervisora de enfermagem me passou total confiança."

O direcionamento das medidas cabíveis para a realização da Comunicação de Acidente de Trabalho (CAT) e o efetivo encaminhamento dos trabalhadores gera estatísticas confiáveis, evitando subnotificações, nas quais as Instituições podem se respaldar para criar Programas de Educação Continuada que nortearão as condutas preventivas e reduzir os números de acidentes ocupacionais (BALSAMO; FELLI, 2006).
A Comunicação de Acidente de Trabalho (CAT) deve ser compreendida pela equipe de enfermagem não como um mecanismo de repreensão, mas sim como um instrumento de excelência fidedigno que tem o propósito de subsidiar dados e proporcionar o direcionamento das medidas preventivas que serão adotadas para reduzir os fatores de risco relacionados aos acidentes.

\subsection{Os profissionais de enfermagem acidentados e as alterações profissionais decorrentes do acidente ocupacional}

O acidente ocupacional, como já mencionado anteriormente, resulta em muitas alterações biopsicossociais no cotidiano do profissional de enfermagem acidentado. Quando indagados a respeito das alterações ocorridas após a vivência do acidente, no âmbito profissional e na maneira de atuar, fica evidente nas declarações a seguir todo esse processo de transformação.

"Estou trabalhando com mais atenção, tomando cuidado para não acontecer novamente"... "Agora trabalho com muito cuidado, me preocupo em utilizar todos EPIs possíveis. Antes me preocupava só em utilizar luvas de procedimento, hoje estou agindo diferente, utilizo máscara e óculos de proteção quando necessário. Não quero passar por todo aquele transtorno novamente"... "Mudei minha postura de trabalhar após o acidente, agora tenho outras condutas, não reencapo agulhas e sempre utilizo luvas de procedimento. Estou 


$\begin{array}{lcrr}\text { sempre atenta } & \text { durante a } \\ \text { manipulação de } & \text { material } \\ \text { perfurocortante e } & \text { secreções } \\ \text { sanguinolentas." } & & \end{array}$

Os trabalhadores de enfermagem, no decorrer de suas atividades, se sentem invulneráveis ao acidente ocupacional, pelo fato de se considerarem experientes e aptos a realizar procedimentos sem a utilização de EPIs (equipamentos de proteção individual) (RIBEIRO; SHIMIZU, 2007). As falas a seguir evidenciam esta questão.

"Não vejo necessidade alguma de alterar minha maneira de trabalhar, porque o que aconteceu foi uma fatalidade e não vai acontecer novamente"... "Não preciso alterar minha maneira de trabalhar, porque no meu caso foi apenas um acidente e raramente ou nunca estou sem atenção."

Alguns profissionais de enfermagem, todavia, relataram não alterar sua maneira de trabalhar em função do acidente ocupacional. Essas declarações demonstram deficiência no conhecimento pertinente à exposição ocupacional e enfatizam a necessidade de Programas de Educação Continuada que enfatizem as medidas de Biossegurança.

\section{CONCLUSÃO}

Ao final deste estudo concluí-se que:

- O perfil profissional do acidentado na instituição investigada caracteriza-se por técnicos de enfermagem, do sexo feminino, adultos jovens, com menor tempo de experiência profissional, atuando no período diurno no setor de Clínica Médica;
- quanto ao conhecimento sobre a necessidade de seguimento sorológico e adoção das medicações prescritas, os profissionais de enfermagem referiram conhecer a importância do seguimento sorológico e da adoção da terapêutica antiretroviral, embora a adesão a esta não tenha sido satisfatória;

- em relação à desistência do tratamento, os entrevistados atribuíram aos efeitos colaterais gerados pela medicação, como intolerâncias gastrintestinais.

A complexidade envolvida no acidente de trabalho remete aos profissionais da equipe de enfermagem um desequilíbrio biopsicossocial, em que afloram as emoções como medo, raiva, nervoso, incapacidade, vazio, desespero e ansiedade, decorrentes dos transtornos psicológicos que o acidente ocupacional ocasiona na vida do indivíduo, embora essa vulnerabilidade muitas vezes não gere alteração no comportamento do funcionário em relação à adequada utilização do Equipamento de Proteção Individual.

Dessa maneira, faz-se necessária a implantação de Ações Educativas, Programas de Educação Continuadas e a instituição de Protocolos aos profissionais da equipe de enfermagem, visando melhor entendimento dos riscos de exposição ocupacional sobre HIV (Vírus da Imunodeficiência Humana), HBV (Vírus da Hepatite B) e HCV (Vírus da Hepatite C).

\section{REFERÊNCIAS}

ALMEIDA, C. A. F. Acidente do trabalho: adesão à quimioprofilaxia dos trabalhadores da saúde pós-exposição a material biológico 
humano. 2003. Dissertação (Mestrado em Enfermagem) - Faculdade de Ciências Médicas. Universidade Estadual de Campinas, Campinas, 2003.

ALMEIDA, C. A. F.; BENATTI, M. C. C. Exposições ocupacionais por fluidos corpóreos entre trabalhadores da saúde e sua adesão à quimioprofilaxia. Rev Esc Enferm USP, São Paulo, v. 41, n. 1, p. 1206, 2007.

BALSAMO, A. C.; FELLI, V. E. A. Estudo sobre os acidentes de trabalho com exposição aos líquidos corporais humanos em trabalhadores da saúde de um hospital universitário. Rev Latino-am. Enfermagem, v. 14 , n. 3, p. 346-53, maio-jun. 2006.

CARVAlHO, A. M. C.; ARAÚJO, T. M. E. Análise da produção científica sobre Hepatite B na pós-graduação de enfermagem. Rev Bras Enferm, v. 61, n. 4, p. 518-22, jul-ago. 2008.

CASSOLI, L. M. Acidente ocupacional com material biológico: adesão ao seguimento ambulatorial segundo as características do acidente e do acidentado. 2006. Dissertação (Mestrado em Ciências) - Faculdade de Medicina, Universidade de São Paulo, São Paulo, 2006.

CASTANHA, A. R.; MACHADO, A. A.; FIGUEIREDO, M. A. C. Consequências biopsicossociais do acidente ocupacional com material biológico potencialmente contaminado: perspectiva de pessoas do convívio íntimo do profissional da saúde. Rev SBPH, v. 10, n. 1, p. 65-84, jun.2007.

CHIODI, M. B.; MARZIALE, M. H. P.; ROBAZZI, M. L. C. C. Acidente de trabalho com material biológico entre trabalhadores de unidades de saúde publica. Rev. Latino- am. Enfermagem, v. 15, n. 4, jul.-ago. 2007. Disponível em: $<\mathrm{http}: / /$ www.scielo.br/pdf/rlae/v15n4/pt_v15n 4a17.pdf>. Acesso em: 27 set. 2010.

CORREIA, C. F.; DONATO, M. Biossegurança em uma unidade de terapia intensiva. A percepção da equipe de enfermagem. Esc Anna Nery Rev de Enferm, v. 11, n. 2, p. 197-204, jun. 2007.

DAMASCENO, A. P. et al. Acidentes ocupacionais com material biológico: a percepção do profissional acidentado. Rev Bras Enferm, v. 59, n. 1, p. 72-7, jan-fev 2006.

GIR, E. et al. Acidentes com material biológico e vacinação contra hepatite $B$ entre graduandos da área de saúde. Rev Latinoam Enferm., v. 16, n. 3, maio-jun. 2008. Disponível em: $<$ http://www.scielo.br/pdf/rlae/v16n3/pt_11.pd f>. Acesso em: 27 set. 2010.

LIMA, F. A.; PINHEIRO, P. N. C.; VIEIRA, N. F. Acidentes com material perfurocortante: conhecendo os sentimentos e as emoções dos profissionais de enfermagem. Esc Anna Nery Rev Enferm, v. 11, n. 2, p. 205-11, jun. 2007

MALAGUTI, S. E. et al. Enfermeiros com cargo de chefia e medidas preventivas à exposição ocupacional: facilidades e barreiras Rev Esc Enferm USP., v. 42, n. 3, p. 496-503, ago. 2008.

MEDEIROS, E. A. S. et al. Eventos adversos relacionados à profilaxia anti-retroviral em acidentes ocupacionais. Rev Saúde Pública, v. 41, n. 2, p. 294-6, abr. 2007.

MEIHY, J.C.S.B.; HOLANDA, F. História oral: Como fazer, como pensar. 1. ed. São Paulo: Contexto, 2007. 
MINAYO, M. C. S. $O$ desafio do conhecimento: Pesquisa qualitativa em saúde. 11. ed. São Paulo: Hucitec, 2008.

MINISTÉRIO DA PREVIDÊNCIA SOCIAL. Lei n.8213, de 24 de julho de 1991. Dispõe sobre os planos de benefícios e dá outras providências. Diário Oficial da União, Brasilia, DF, 14 ago. 1991. Disponível em: <http://www010.dataprev.gov.br/sislex/pagin as/42/1991/8213.htm>. Acesso em: 16 out. 2010.

MINISTÉRIO DA SAÚDE. Cadernos de atenção básica. Série A Normas e Manuais Técnicos: HIV/Aids e outras DST. $\mathrm{n}^{\circ} 18.1^{\circ}$ ed. Brasília. 2006. Disponível em: http://bvsms.saude.gov.br/bvs/publicacoes/a bcad18.pdf. Acesso em: 23 mar. 2008.

MINISTÉRIO DA SAÚDE. Ficha de Investigação de Acidente de Trabalho com Exposição à Material Biológico. Secretaria de Estado de Saúde. Sistema de Informação de Agravo de Notificação. Disponível em: http://www.crt.saude.sp.gov.br/resources/crt aids/fichasdenotificacaoepidemio2009/acidtr _expbio_net.pdf. Acesso em: 23 mar. 2008.

MINISTÉRIO DA SAÚDE. Recomendações para $o$ atendimento e acompanhamento da exposição ocupacional a material biológico: HIV e Hepatites B e C. Brasília. 2004. Disponível em:

http://www.aids.gov.br/data/documentsstored Document7BB8EF5DAF23AE4891AD36190 3553A3174\%7d7B9475AA3B8D39451F96B 161E304383788\%7D/manual acidentes20fi nal.pdf. Acesso em: 23 mar. 2008.

PINHEIRO, J.; ZEITOUNE, R. C. G. Hepatite $B:$ Conhecimento e medidas de biossegurança e a saúde do trabalhador de enfermagem. Esc Anna Nery Rev Enferm, v. 12, n. 2, p. 258-64, jun. 2008.
PINHO, D. L. M.; RODRIGUES, C. M.; GOMES, G. P. Perfil dos acidentes de trabalho no Hospital Universitário de Brasília. Rev Bras Enferm, v. 60, n. 3, p. 291-4, maio-jun. 2007.

RIBEIRO, E. J. G.; SHIMIZU, H. E. Acidente de trabalho com trabalhadores de enfermagem. Rev Bras Enferm, v. 60, n.50, p. 536-40, set.-out. 2007.

SAILER, G. C.; MARZIALE, M. H. P. Vivência dos trabalhadores de enfermagem frente ao uso dos antiretrovirais após exposição ocupacional a material biológico. Texto Contexto Enferm., v. 16, n. 1, p. 55-62, jan.-mar. 2007.

SARQUIS, L. M. M.; FELLI, V. E. A. Recomendações em saúde aos trabalhadores expostos a fluidos biológicos. Rev Mineira Enferm., v. 12, n. 3, p. 381-389, jul.-set. 2008.

SARQUIS, L. M. M. et al. A adesão ao protocolo de monitoramento dos trabalhadores de saúde após exposição a fluidos biológicos: uma problemática vivenciada em um ambulatório de saúde do trabalhador no Paraná. Cogitare Enferm, v. 10, n. 2, p. 47-53, maio/ago. 2005.

SCHEIDT, K. L. S.; ROSA, L. R. S.; LIMA, E. F. A. As ações de biossegurança implementadas pelas comissões de controle de infecções hospitalares. Rev Enferm UERJ, v. 14, n. 3, p. 77-372, jul.-set. 2006.

VIEIRA, M.; PADILHA, M. I. C. S. O HIV e o trabalhador de enfermagem frente ao acidente com material perfurocortante. Rev Esc Enferm USP, v. 42, n. 4, p. 804-10, dez. 2008. 